\title{
Clean Coal \& High Carbon Efficiency Energy Engineering
}

\author{
Stefan Petters ${ }^{1,2}$, Kalvin Tse ${ }^{2}$ \\ ${ }^{1}$ BoD of guo-Business Development Consult Vienna, Austria \& Bestrong International Ltd, Hong Kong, China \\ ${ }^{2} \mathrm{R}$ \& D Bestrong International Ltd, Hong Kong, China \\ Email: go@int88.biz
}

Received January 2015

\section{Abstract}

Today we live in a world of Hydrocarbon Energy Carriers, where Carbon is always used as a Carrier for Hydrogen 1) Biomass $\left(\mathrm{CH}_{1.44} \mathrm{O}_{0.66}\right.$ or $\left.\mathrm{C}_{6} \mathrm{H}_{12} \mathrm{O}_{6}\right)$; 2) Natural Gas [NG] $\left(\mathrm{CH}_{4}\right)$; 3) Water Gas $\left[\mathrm{C}+\mathrm{H}_{2} \mathrm{O}\right]$; 4) Gasoline $\left(\mathrm{C}_{6} \mathrm{H}_{12}, \mathrm{C}_{7} \mathrm{H}_{18}, \mathrm{C}_{8} \mathrm{H}_{18}\right.$, etc. $\left.) ; 5\right)$ Kerosene $\left(\mathrm{C}_{17} \mathrm{H}_{36}, \mathrm{C}_{18} \mathrm{H}_{38}, \mathrm{C}_{19} \mathrm{H}_{40}, \mathrm{C}_{20} \mathrm{H}_{42}, \mathrm{C}_{21} \mathrm{H}_{44}\right.$, $\mathrm{C}_{22} \mathrm{H}_{46}$, etc.) and; 6) Crude Oil. The Carbon aggregates are all storable and have worthwhile, logistically manageable energy densities. But whenever recovering Energy from the Carbon molarities, $\mathrm{CO}_{2}$ gets emitted into the atmosphere, while separate use of Hydrogen Energy contents carried by the Carbon moieties would just generate water vapor. Hydrogen is also the most important intermediary in Refineries, hydrogenating lower grade Hydrocarbons into higher potencies, or for removing Sulfur by the formation of Hydrogen Sulfur, that can be dissociated after its segregation from the Hydrocarbon products. But most of the internal Hydrogen yields in Refineries today is used for onsite production of Ammonia as a basis for Energy fertilizers in high performance agriculture. Because Hydrogen is awkward to store and transport, most of it is currently used captive within large size centralized plants as a reactant for producing Hydrocarbon energy carriers, using the Carbon as a carrier for the Hydrogen moieties, to then be distributed over big enough areas for consumption of the such large scale plants' volumes. With recently proven achievements of Hydrogen production from excess Wind \& Solar Power by electrolysis, Hydrogen could become available in abundant quantities, to be distributed locally within the coverage area of the transmission grid such Wind \& Solar installations are feeding into. In combination with Carbon as a reactant such abundant Hydrogen could also be synthesized into Hydrocarbon Energy Carriers and substitute fossil commodities.

\section{Keywords}

Atmospheric Carbon, Carbon Efficiency, Carbon Metabolism, Carbon Re-Use, Chemical Energy Content, Controlled Microbial Composting, Energy Carriers, Fossil Substitute Commodities, Intermediaries, Heating Value, Hybrid Power Plant, Hydrocarbon, Hydrogen, Organic Waste Valorization, Photosynthesis, Productivity, Refineries

\section{Introduction}

Unfortunately Energy Engineering had been driven mostly by sectorial views. 1) Humans tend to feel more 
comfortable when segregating issues into isolated segments. So solutions to problems found, often ignored important nexus'. 2) And if we look at mankind's problem solving practice, most often we find the "more of the same" as well as the "bigger the better" models. 3) As long as something plentifully available and inexpensive works, we tend to use it wastefully. 4) Anything not having any obvious value predominantly is left aside and disregarded. 5) Last but not least, in case of adverse knock-on effects of a developed practice, abatement strategies prevail over root-cause mitigation approaches. In the name of Productivity Energy Technologies had been focusing on ever increasing grade of fuels, rated by the heating value as a measure for the Chemical Energy content of it. Isn't it symptomatic for our mind sets, that it's called "Heating Value"! Obsession for quickest and supposedly cheapest solutions drove most conventional Energy Engineering simply by secondary energy yield objectives. Since the invention of steam engines the process chain for fuel use is always its combustion to heat for transformation into mechanical work. Today's Combined Heat and Power standard brags with the use of "Waste-Heat" being just transformation losses in reality.

But the biggest show-stopper of combustion in large scale is that thermo-chemical processes always need continuous operating conditions, irrespective of whether the output heat can be fully consumed or not. And what we don't use, we lose.

Refineries, also thermo-chemical plants, of course need continuous operations as well, but do not destroy the feedstock's Chemical Energy content. They transform it into higher grade Hydrocarbon Energy Carriers, whereas waste heat in the process chain can often be used onsite to actuate intended chemical reactions, helping to achieve good Output per Input Efficiencies. Unfortunately these achievements have so far almost only been applied for liquid or gaseous fossil primary Energy Carriers and in very few examples only for some high grade coal solid fuel applications, also being fossil energy.

Could it be that the future is obviously already among us, just not dissipated, interpreted and applied in the most favorable ways for us?

\section{Questions on Best Available Technologies}

\subsection{Energy Intensity and Carbon Efficiency}

According to Lawrence Livermore National Laboratory [US] the total 2013 Energy consumption of the USA was $40 \%$ efficient only, relative to the primary energy used, whereof $82 \%$ were from non-ambient carbonaceous energy carriers (60\% were just wasted).

Projections for 2025 promise an efficiency improvement of 12.5\%-assuming an increase of carbonaceous energy carriers of $8.6 \%$ (so Green House Gas Emissions for wasted energy will actually grow proportionally with the increase in consumption).

It would however not be unusual for the USA, if things came differently-there is very interesting developments going on, contradictory to the projections of the Department of Energy, supported by the Department of Defense-namely in the field of Bio-Refineries from MSW residues, going for Fossil substitute Commodities.

\subsection{Bio-Refinery Technologies}

4 years ago the term Bio-Refinery enjoyed 150 citations in scientific papers. Around that time several groups involved in abundant organic matter valorization had demonstrated full feasibility of biomass or organic waste decomposition into energy rich gases as well as chemical synthesis from their Hydrogen and Carbon monoxide fractions.

While in Europe only Biomass conversion into Substitute Natural Gas or CHP electricity was supported into Lighthouse project implementations [1], the US Department of Defense supported a first time implementation for waste valorization into jet-fuels. Because of conditions precedent in the USA, where there is no market for Refuse Derived Fuels [RDF] due to cheap enough availability of Natural Gas, not needing flue gas clean-up, RDF has no value and energy is considered cheap enough to use auxiliary energy for transformation processes. On that basis demonstration looked economic enough for Hong Kong airline Cathey Pacific to invest into a roll-out of a RDF to jet-fuel project!

\section{China's Growth Strategy Model}

China's fast and flexible capacity building capabilities facilitated remarkable poverty reduction over the last 20 
years. But in this historic model China had been building on a Quantitative Growth Strategy model [2]. It works by crowding out competition through scale of economy advantages from shedding complexities for highest possible segmental efficiencies and maximizing demand by advertising customer expectations you can fulfill for the best scale of economy for each product.

A Qualitative Growth Strategy model relies upon building up capabilities followed by allocation of markets in need for it [3]. By developing the best fit for every application it creates additional added value, avoiding waste redundancies or adverse consequential remedies under the use of available synergies.

\subsection{Coal Gas Projects Seen in China}

Currently used Technology in Coal Gas seems to run at fuel to steam ratios of $\sim 4$, which at an average of $85 \%$ Carbon content in the coal processed, would represent a steam to Carbon ratio of almost 5 [4]. That is about 3 times the theoretic technical need—can this be the right Technology for coal rich geological areas, usually not blessed with a lot of water?

\subsection{Carbon Efficiency Increase Springboards}

- China has impressively demonstrated to cumulate experience towards highly competitive supply capability for Solar or Wind generation plants and over the last 2 years led the world in new installations, ranking global number one now in installed capacity.

- Companies like Dragon Power Industries have been very successful in developing renewable electricity by energy recovery plants from straw biomass, after coming up with a standardized solution of awkward logistics' challenges related to straw.

- Over the last 5 years we have seen lots of progress in municipal waste water treatment capacities. Unfortunately however add-on solutions for sewage sludge discharge, requiring inertization and minimization of final sink disposal space are still lacking behind.

- Our testimonial of scientific collaboration between the Austrian University sector and Chinese Academy of Science highly admires the in depth investigations and knowledge of Chinese Scientists on Coal as a solid fuel. While there is a lot of remarkable expertise in China, how to upgrade coal prior to its use, the Austria has been peering the in clean use of poor carbonaceous fuels for the past 10 years already [5] (Canada, Sweden and France all came to license it in).

- Waste has become an expensive burden to China's urban citizens. Incineration, widely considered being Best Available Technology is financially not self-sufficient and even less economic, wherever its logistics involve an informal sector (as being the case in China). They pick anything that is valuable as a direct recyclable, reusable or Refuse Derived Fuel (Energy Recovery) item and leave the waste sector just the putative invaluable residues [6].

\subsection{Innovation}

There may be many business people who make or administrators who take money out of others, but fail to add new value to society. The world has cumulated so much menace to life on our planet, because there are too few fearless people, having vision, passion persistence and open minds to learn from each other how to implement or execute economically self-sufficient solutions, that can improve or ease peoples' lives = Innovation.

China working on multiyear planning horizons on the other hand could actually provide uniquely suitable cycle time conditions precedent for Innovation based Qualitative Growth.

\section{Reducing China's Carbon Intensity}

At the first IAEE-Asia Conference held in China, 2014, opening remarks China's political demand for reducing Energy Intensity and an increase of Carbon Efficiency was clearly stated [7]. Of course an Energy mix relying more than 2/3 on coal, opens a lot of perspectives for Carbon Efficiency improvements by either reducing Energy Intensity or replacing coal by Natural Gas, particularly in conjunction with New Renewable Energy back-up requirements. There are enough concepts in place at higher per capita income countries that may tempt China to import. But unfortunately none of these fulfill the most important condition precedent of Sustainability—namely: "financial self-sufficiency under arms' length market price business conditions” — Not perceived to 
be fulfilled by today’s New Energy sectors, whether it was renewable or unconventional gas! In all these sectors achievements have been reached at the expense of tax-payers, consumers or investors.

Therefore delivery of China's political demand will require Innovation. For that we would suggest an integration of proven Technology elements into new combinations of hybrid Energy Systems.

\subsection{Retaining Energy in Storable Aggregates}

Decentralized configurations of waste heat induced Energy generation can enjoy economic opportunities from district heating or cooling, as often demonstrated in so called Waste-to-Energy configurations (where secondary resource feedstock's Energy is just scantily recovered).

1) System Effectiveness of solid fuel fed plants could be significantly uplifted if direct combustion = stored energy release into secondary energy and $\mathrm{CO}_{2}$ - was replaced by gasification = retaining bigger part of stored chemical energy in transformed storable moieties-and using only unconverted fractions for auto-thermal transformation energy alimentation. This would yield following advantages:

a) Any fuel poisons could be separated from the non combusted anoxic hydrocarbon product gas mix in forms that even allow elementary recoveries.

b) Downstream use of the product gas, volatilized from the solid fuel feedstock can be spread over several usage paths and/or allotted independently from the feedstock input cycle, according to final output demand time patterns.

c) Excess product gas output from solid fuel input represents unconsumed Chemical Energy and can be used in Chemical Synthesis production of Fossil substitute Commodities.

2) Combining above described Solid Fuel Refinery with excess New Renewable Energy Power to Gas electrolysis of Hydrogen allows [8]:

a) sharing temporary storage facilities as well as the hardware for utility scale Hydrogen Fuel Cell back-up electricity generation for New Renewable Energy grid with waste-heat use within district heating or cooling.

b) extension of the product portfolio spectrum for Chemical Synthesis of fertilizer, fuels and/or polymers.

c) preparing Hydrogen Mobility distributed fuel production, saving long haul transportation of Hydrogen [9].

\subsection{Refining Ambient versus Fossil Carbon}

As already outlined in the Abstract, biomass actually represents a Hydrogen rich solid carbonaceous fuel [10]. Simple combustion for so called Energy Recovery just neglects this uniqueness and just follows traditions of prehistoric men.

Biomass actually represents a suitable feedstock for Hydrocarbon transformation refineries. By using it as a feedstock for chemically synthesizing Fossil substitute Commodities from its decomposition gases we can achieve Re-Use of ambient Carbon.

This applies equally to any organic waste or residues, whether originating from harvested biomass, fermentation sludge or fossil derived MSW fractions. All of this represents potential atmospheric Carbon stock if turned into $\mathrm{CO}_{2}$ by incineration or biological degradation, sometimes even to 23 times as aggressive $\mathrm{CH}_{4}$ emission.

Solid low grade fuel refining has been being developed in Austria over the last 30 years from stationary to fast internally circulating bed gasification reactors. Today's state of art has arrived at "Fast Internal Circulating Dual Fluidized Bed" [FICDFB] gasification proven in a multiyear $>7,000 \mathrm{hrs} / \mathrm{a}$ operation at Oberwart [11]. Recently FICDFB Technology was licensed out to Sweden and France for lighthouse projects (of Gothenburg-Gas and GDF-Suez respectively) [12].

\subsection{Clean Coal Use}

Steam-Driven FICDFB Gasification yields two separate gas output streams: a) Flue Gas Stream $\left(12 \% \mathrm{CO}_{2}\right.$, $6 \%$ $\mathrm{O}_{2}, 83 \% \mathrm{~N}_{2}$ ) from the combustion chamber, where the char residue of the anoxic, fast pyrolysed (thermo-chemically cleaned) feedstock gets combusted, and $\mathrm{b}$ ) product gas stream, which includes the typical fuel poisons in the form of hydrates, e.g. $\mathrm{H}_{2} \mathrm{~S}, \mathrm{NH}_{3}$ or $\mathrm{HCl}$, allowing cleaning by ways of enabling reuse of the same.

The solid fuel transformation into usable energy is here induced by heat from the fast circulating ( $\sim 50$ times/h) Bed Material (i.e. mineral sand) as a heat transfer medium between the Combustion (oxygenic) and Gasification (anoxic) chamber. This becomes possible, as unconverted Carbon ends up intermixing into the bed-material and 
as schematically shown in Figure 1 moves onward with the sand to the Combustion chamber, where the air supply, rising the sand back up to the recirculation loop into the Gasification chamber, lights the char up (alike in a smith oven) and heats the sand during its rise.

The Gasification chamber is a bubbling bed, fluidized by water steam, effecting fast high temperature Pyrolysis followed by a steam reforming water shift equilibrium reaction in the free board zone above the bed's splash zone, as illustrated in Figure 2.

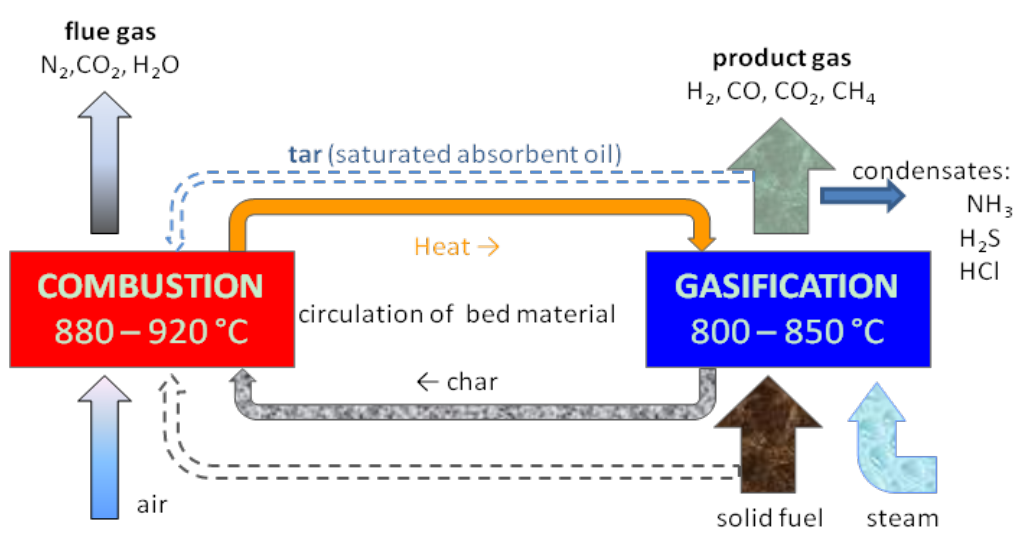

Figure 1. FICDFB functional scheme.

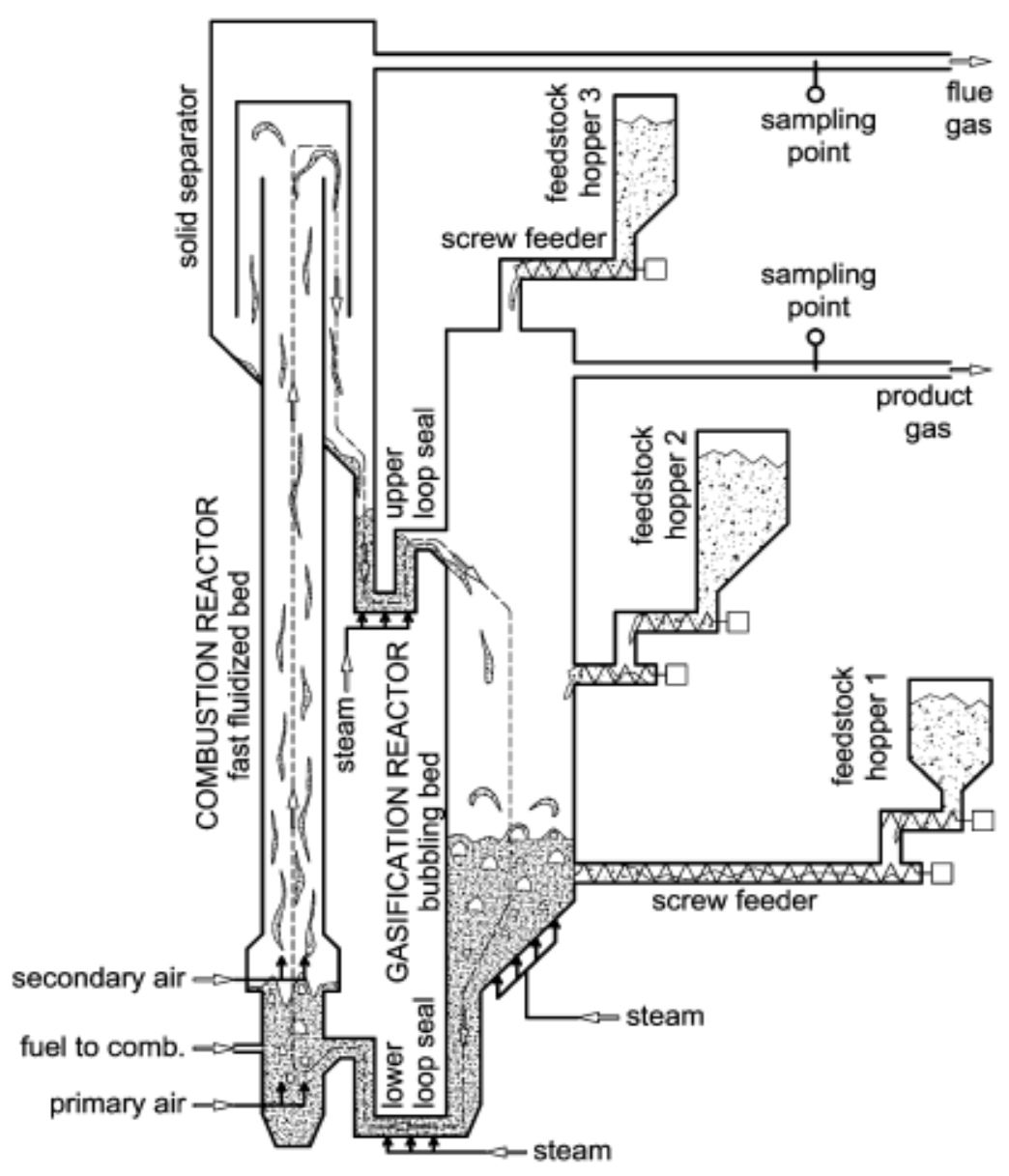

Figure 2. FICDFB reactor. 
One of the merits of this process for thermo-chemical decomposition of solid carbonaceous fuels is its wide tolerance to varying feedstock qualities and composition. Originally developed as enhancement in sewage sludge incineration FICDFB can process up to $40 \%$ moisture in the feedstock, different materials, as Refuse Derived Fuel, Biomass, Coal, sludge of fermentation residues at the same time from parallel feeders at varying positions of the reactor, as long as the compounded average Lower Heating Value of the solid fuel mix results in $\geq 10 \mathrm{GJ} /$ ton [13]. A practical application example is illustrated in Table 1 and Figure 3.

\subsection{Clean Coal Use}

We have seen various initiatives in China to optimize coal quality prior to its use, such as coking plants or dry distillation installations.

While all coal purification efforts seen in China are economically affected by scrape rates, FICDFB can either process the low grades falling off from such existing purification processes, or save the extra purification step and use the original coal as is in a clean manner [14]. However, the scales we have commonly seen in Chinese coal industry, would need to be downsized for FICDFB.

In terms of the water nexus a broader geographic dispersion of capacities over the territory should however be quite advantageous. In addition FICDFB operates at a Steam to Carbon ratio of 1.8:1, which at a manageable moisture content of feedstock in the order of $30 \% \pm 33 \%$ results in a Steam to Fuel ratio of $1-1.4: 1-1 / 3$ of what we have seen in China's large scale coal-gas installations.

\subsection{The Economics of Smaller Scales}

Of course in mechanical devices like turbines or hydraulic presses, etc. scale may be an advantage. But is it equally true for chemical reactors? Maybe anything bigger than standard size steel tubes available on the market, needing to replace industrial volume produced components by special handcraft on site construction, may be more expensive to build than larger volume factory made series of smaller units.

Coming from industrial mass production, we know well that synchronization of capacities linked into a process chain is a much stronger key to overall economics than a singular process step's scale of economy.

Therefore we consider scale much less important than potential economics of synergies between process steps hybridized into a total system. Flexibility in process chain sequence for mitigation of resource losses often pays off any additional investments needed for it, in a fraction of time required to amortize the basic system's investment.

\subsection{Hybridizing Thermo- \& Electro-Chemical $\mathrm{H}_{2}$}

Since FICDFB is limited in scalability and therefore best suitable for decentralized local feedstock use, it could easily be combined with vicinal New Renewable Energy generation back-up measures in the area [15].

China having its genuine own Coal resources has been internationally pressured to switch coal to Natural Gas [16], as thermal power from Natural Gas comes at $~ 50 \%$ the $\mathrm{CO}_{2}$ Emissions than from Coal.

In this example $34 \%$ of $E_{\text {chem }}$ would be contributed from Ambient Carbon Stock, of which $60 \% E_{\text {chem }}$ is contributed by the Hydrogen contents of biomass \& RDF-resulting in a 54\% reduction of accountable Green House Gas Emissions compared to heat from coal only - Coal could be co-used cleanly at identical fossil emissions as Natural Gas would cause for the same Heating Value, if compounded with ambient Hydrocarbon residues [17].

\section{Conclusions}

China’s Energy Engineering could uplift sustainability standards significantly, if entrepreneurial spirit could be

Table 1. Typical feedstock lower heating values.

\begin{tabular}{ccccc}
\hline \multirow{2}{*}{ Lower Heating Value } & \multicolumn{3}{c}{ Type of Feedstock } \\
\cline { 2 - 5 } & Lignite & or & Biomass & $C N-M S W$ \\
\hline $\mathrm{GJ} / \mathrm{t}$ & 20 & & 17 & 6.5 \\
$\varnothing \geq 10$ & $\geq 35 \%_{\mathrm{wt}}$ & or & $\geq 41 \%_{\mathrm{wt}}$ & $\leq 46 \%_{\mathrm{wt}}$ \\
\hline
\end{tabular}




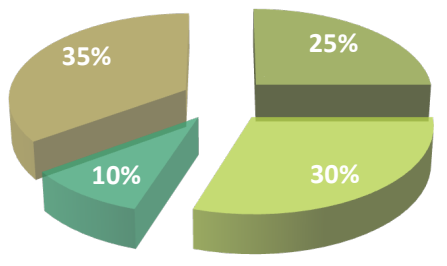

$$
\begin{aligned}
& \text { AD Sludges } \quad \text { Org. Residue } \\
& \text { RDF in MSR } \quad \text { Lignite }
\end{aligned}
$$

Figure 3. Example of a mixed fuel MSW \& sludge.

enticed to tap on China's unique positions in New Renewable Energy installations and Carbon refining expertises from coal know how. Hybridization of decentralized electricity generation from Solar and/or Wind energy with Power to Gas back-up Hydrogen electrolysis and MSW and/or Biomass Carbon refining, leveraged with up to $1 / 3$ coal, would be an enormous People Planet Profit opportunity. There is a need for 25,000 MSW refining plants and room for another 50,000 agricultural and industrial organic waste Bio-Refineries in the world. This could lead to a new industry of similar order of magnitude like global commercial airplane industry, turning at a building rate of 800 units per year. At such production level the MSW sector alone would give a 30 year task to such new industry.

Last but not least the proposed hybridization with excess New Renewable Electricity Electrolysis Hydrogen could overcome the struggles with intermittency without enormous investments into storage solutions. At the same time it could increase bio-refineries' chemical synthesis Carbon Re-Use capabilities by $~ 30 \%$. Changing the excess production paradigm in Energy Engineering to decentralized hybrid grids, producing secondary energy from continuous thermo- or bio-chemical processes only on demand and indirectly, would help shave volatile intermittency of temporarily insufficient New Renewable Production and allow to keep recoverable exergy from primary or secondary resources in logistically flexible to handle, storable chemical aggregates.

Apart from minimizing yet unresolved storage issues for New Renewable Energy such arrangements would guarantee higher plant usage rates for all assets installed. At the same time Energy Efficiency losses from idling back-up operations could be eliminated and thus uplift Carbon Efficiency and reduce Primary Energy Intensity. Last but not least this model could save having to build incinerators and turn large part of waste remediation cost into a value adding positive GDP contribution.

\section{References}

[1] Burman, Å. (2013) The GoBiGas-Project. SGC 2013, Goteborg.

[2] Petters, S. (2014) Shifting from Quantitative to Qualitative Growth Strategies. Taiyuan University of Technology Staff-Lecture, China.

[3] Stern, S. (2013) Global Innovation and Entrepreneurship. MIT-ILP Europe Conference, Vienna, May.

[4] ACEE (2014) China Unconventional Gas Forum. Chifeng, August.

[5] Xu, G.W. and Hofbauer, H. (2014) Closing Remarks. Vienna University of Technology. iSGA-4 Joint Conference, Vienna, September.

[6] Newman, D. (2013) Closing Session. ISWA World Congress, Vienna, October.

[7] Zhang, G.B. (2014) New Requirements to Energy Researchers (Opening Remarks). 4th Asian and 1st China IAEE Conference, Beijing, August.

[8] Meerman, J.C. (2011) Flexible Gasification Cogeneration Facilities. ICPS 2011, Vienna, September.

[9] Petters, S. (2013) Sustainable Green Hydrogen Production. Regional Project for Clean Transportation, County of Arkershus and Oslo, November.

[10] Hofbauer, H. (2014) Hydrogen from Biomass via Thermo-Chemical Route. A3PS Conference, Vienna, October.

[11] Bosch, K. (2013) Status Report of DFB Gasification Biomass Power Station Oberwart. Renewable Electric Energy Conference, Salzburg, December.

[12] Gros, S. (2013) $\mathrm{CO}_{2}$ Recycling in a Steam Gasifier for SNG or FT-Diesel Production $\mathrm{ReCO}_{2}$ Project. Swedish Gas 
Conference, Sweden, October.

[13] Kern, S., Pfeifer, C. and Hofbauer, H. (2013) Gasification of Low Grade Coal in SD-DFB Gasification. Energy Technology, 1, 253-264. http://dx.doi.org/10.1002/ente.201300009

[14] Kern, S., Pfeifer, C. and Hofbauer, H. (2013) Co-Gasification of Wood and Lignite in a Dual Fluidized Bed Gasifier. Energy Fuels, 27, 919-931. http://dx.doi.org/10.1021/ef301761m

[15] Diwald, W. (2011) Hydrogen-Grid \& Storage Solutions for Renewable Energies. F-Cell Conference, Stuttgart, September.

[16] Sterns, M. (2013) Various Podium Discussions. Eco-Forum, Guiyang, June.

[17] Tse, K. (2014) MSW-Residue \& Coal Co-Gasification in Lieu of Incineration. iSGA-4, Vienna, September. 